\title{
A Cross-sectional Study of Prevalence of Autism Spectrum Disorder among Children Referred for the Assessment of Intellectual Disability for Certification and Its Association with Behavioral and Medical Issues
}

\author{
Shankar Kumar ${ }^{1} \odot$, Sneha Venkatakrishna ${ }^{2} \odot$, Sharon Ruth $^{3}$, Sushmitha Kota ${ }^{4} \odot$, Vedamurthy Bilagehalli Nanjappa ${ }^{5}$
}

\begin{abstract}
Introduction: Intellectual disability (ID) is one of the strongest predictors of outcomes for those with autism spectrum disorder (ASD). Behavioral problems that are commonly observed in autism may be related to the core features of ASD or comorbid diagnoses.

Aims: To assess the prevalence of ASD in those with ID referred for disability assessment and the associated medical and psychological comorbid issues.

Materials and methods: The present study was a cross-sectional study that included 133 children with mild or moderate ID between 6 and 18 years of age. The study tools used were Indian Scale for Assessment of Autism (ISAA), Behavior Problems Inventory (BPI), and a questionnaire to assess medical symptoms.

Results: The prevalence of comorbid ASD in children with ID was $16.39 \%$. Individuals with ASD had higher behavioral problems $(p=0.001)$ and medical issues that included gastrointestinal (Gl) symptoms (constipation, $p=0.001$; bloating, $p=0.03$; and abdominal pain, $p=0.03$ ) and seizure $(p=0.002)$. Children with severe ASD scores had higher behavioral problem scores.

Conclusion: Individuals with ID who were referred for disability assessment had a significant prevalence of ASD. These children had higher behavioral problems and medical issues. It is thus important to screen for ASD in individuals with ID for better management of these individuals. Keywords: Autism spectrum disorder, Comorbidities, Intellectual disability, Behavioral problem.

Indian Journal of Private Psychiatry (2021): 10.5005/jp-journals-10067-0080
\end{abstract}

\section{INTRODUCTION}

According to the American Association of Intellectual and Developmental Disabilities, intellectual disability (ID) is characterized by significant limitations (two standard deviations below average) in intellectual functioning and adaptive behaviors. Autism spectrum disorders (ASD) are characterized by persistent deficits in social communication and restricted patterns of behavior, activities, or interests. ${ }^{1}$ Comorbid ID is probably a strong factor associated with outcomes for individuals with ASD. ${ }^{2}$ Recent literature is suggestive of one in four individuals with ID has comorbid ASD. ${ }^{3,4}$

Estimated rates of ASD-ID comorbidity vary between 25 and $70 \%$ as per studies. ${ }^{5-14}$ In India, the estimated prevalence is $1-2$ per 1,000 to about 1 in $250 . .^{15}$ There is a trend of increasing incidence of ASD, which has been observed in the past few years. ${ }^{16}$ ID in children with ASD, which was initially thought to be as high as $75 \%$, currently seems to be much lesser at $40-55 \%$, which is probably due to higher detection of individuals with high functioning ASD that seems to be more prevalent. ${ }^{17}$ A previous study detected a prevalence of $19.8 \%$ of ASD in individuals diagnosed with ID. ${ }^{18}$

Previous literature has cited that around $7-15 \%$ of individuals with ID have significant behavioral problems. ${ }^{19}$ Behavioral problems that are common in autism may occur due to comorbid diagnoses and core symptoms of autism, such as aggression, disruption, hyperactivity, self-injury, or sensory abnormalities associated with ASD. Comorbid medical conditions, such as gastrointestinal (GI) symptoms, seizures, immune system dysregulation, difficulties in
1-5 Department of Psychiatry, Bangalore Medical College and Research Institute, Bengaluru, Karnataka, India

Corresponding Author: Shankar Kumar, Department of Psychiatry, Bangalore Medical College and Research Institute, Bengaluru, Karnataka, India, Phone: +91 9844546083, e-mail: shankarkjs@ gmail.com

How to cite this article: Kumar S, Venkatakrishna S, Ruth $S$, et al. A Cross-sectional Study of Prevalence of Autism Spectrum Disorder among Children Referred for the Assessment of Intellectual Disability for Certification and Its Association with Behavioral and Medical Issues. Ind J Priv Psychiatry 2021;15(1):38-41.

Source of support: Nil

Conflict of interest: None

feeding (refusal, selectivity, and sensitivity to textures), and sleep disruption, can also occur in ASD.

There is a paucity of Indian literature on the prevalence of ASD among individuals with ID and also on the prevalence of behavioral problems in this population. The present study was undertaken in this background.

\section{Aims and Objectives}

- To assess the prevalence of ASD among children referred for the assessment of ID.

(o) The Author(s). 2021 Open Access This article is distributed under the terms of the Creative Commons Attribution 4.0 International License (https://creativecommons. org/licenses/by-nc/4.0/), which permits unrestricted use, distribution, and non-commercial reproduction in any medium, provided you give appropriate credit to the original author(s) and the source, provide a link to the Creative Commons license, and indicate if changes were made. The Creative Commons Public Domain Dedication waiver (http://creativecommons.org/publicdomain/zero/1.0/) applies to the data made available in this article, unless otherwise stated. 
- To assess the various behavioral and medical problems and their correlation with these children.

\section{Materials and Methods}

Institutional Ethical Committee clearance was taken before initiating the study. This study was undertaken in the Department of Psychiatry of a tertiary care general hospital. It was a crosssectional study undertaken over a period of 4 months. Purposive sampling was used, and 162 participants ( 74 females and 88 males) aged 6-18 years with ID referred for disability assessment were included in the study.

\section{Study Tools}

- A semi-structured questionnaire with details of medical history was administered. Questions on the following medical symptoms that are described in children with ASD were asked, which included questions on (a) Gl symptoms such as diarrhea, constipation, bloating, nausea/vomiting, and abdominal pain; (b) allergies and atopy such as skin allergies and asthma; (c) autonomic symptoms such as giddiness/fainting; and (d) central nervous system symptoms such as seizures and recurrent headaches. ${ }^{20,21}$

- Behavioral Problem Inventory (BPI): It is an informant-based behavioral rating scale to assess maladaptive behaviors in persons with developmental disabilities. BPI is typically scored on two aspects-frequency of behavioral problem on a Likert scale of $0-5$ and severity of symptoms on a scale of $0-3$. Severity score was used for the analysis.

- Indian Scale for Assessment of Autism (ISAA): It is an Indian scale that is used for the assessment of disability in ASD. It has 40 items divided under six domains; each item being rated in increasing severity of 1-5. A score of $<70$ indicates no autism, 70-106 (mild autism), 107-153 (moderate autism), and >153 (severe autism).

\section{Method}

Intelligence quotient (IQ) assessment was done on 162 study participants. Binet Kamat Test of intelligence was used for verbal children and Vineland Social Maturity scale for other children. One-hundred and thirty-three children with mild and moderate ID were screened for ASD using the ISAA after obtaining consent from parents. Those with severe and profound intellectual or developmental disability were excluded from the study as symptom presentations of severe ID tend to overlap with ASD and would necessitate detailed clinical assessment that was not done.

Sociodemographic details that were obtained using a semistructured questionnaire that also looked into the medical history was administered. Behavioral problems were assessed using BPI. Data obtained were analyzed using descriptive statistics and $t$-test for continuous variables and Chi-square test for categorical variables. Results obtained were compared with previous studies, and conclusions were drawn.

\section{Results}

Prevalence of ASD in subjects with mild and moderate ID was $16.54 \%(n=22)$.

We found that children with ASD were significantly younger, whose parents had less income (in rupees), than those without ASD (Table 1).

Table 2 compares medical symptoms between those with and without ASD. It shows that children with ASD significantly had higher Gl symptoms, such as constipation, bloating, and abdominal pain. Also, they had higher seizure history than those without ASD.

Table 1: Comparison of sociodemographic profile between children with and without ASD

\begin{tabular}{|c|c|c|c|}
\hline & $\begin{array}{c}\text { Children with ASD (22) } \\
\text { Mean (SD) }\end{array}$ & $\begin{array}{l}\text { Children without ASD } \\
(n=111) \text { Mean (SD) }\end{array}$ & $t$ test/Chi-square test ( $p$ value) \\
\hline Age (in years) & $7.87(1.33)$ & $9.71(2.44)$ & $3.32\left(0.0012^{\mathrm{a}}\right)$ \\
\hline Urban background & 12 & 85 & $1.46(0.2)$ \\
\hline Children receiving special education & 14 & 98 & $2.7(0.09)$ \\
\hline Income of parents (rupees) & $12,535(3,446)$ & $18,797(4,385)$ & $6.01\left(0.001^{\mathrm{a}}\right)$ \\
\hline Children receiving psychotropics & 09 & 45 & $0.1(0.65)$ \\
\hline
\end{tabular}

${ }^{\mathrm{a}}$ Represents $p \leq 0.05$ considered as statistically significant

Table 2: Comparison of medical symptoms in children with and without ASD

\begin{tabular}{lccc}
\hline & Children with ASD (22) & Children without ASD $(n=111)$ & Chi-square test ( $p$ value) \\
\hline Diarrhea & 3 & 12 & $0.03(0.86)$ \\
Constipation & 7 & 6 & $9.66\left(0.001^{\mathrm{a}}\right)$ \\
Bloating & 6 & 8 & $4.29\left(0.03^{\mathrm{a}}\right)$ \\
Nausea/vomiting & 2 & 5 & $0.22(0.63)$ \\
Abdominal pain & 7 & 15 & $4.25\left(0.03^{\mathrm{a}}\right)$ \\
Skin allergies & 5 & 18 & $0.01(0.91)$ \\
Asthma & 1 & 5 & $0.01(0.91)$ \\
Giddiness/fainting & 3 & 3 & $0.89(0.34)$ \\
Seizures & 9 & 12 & $9.15\left(0.002^{\mathrm{a}}\right)$ \\
Recurrent headaches & 3 & 5 & $0.22(0.63)$ \\
\hline
\end{tabular}

${ }^{\text {aRepresents }} p \leq 0.05$ considered as statistically significant 
Table 3 compares mean scores of ASD, IQ, and behavioral problems between those with and without ASD. Children with ASD had lower IQ, higher ASD scores on ISAA, higher total behavioral problems as well as self-injurious behavior, stereotyped behavior, and aggressive behavioral scores on BPI.

Table 4 compares behavioral problems between children with mild and moderate ASD. Children with moderate autism significantly had higher behavioral problems than those with mild autism. There was no significant difference seen in autism scores among mild and moderate ID groups, which is illustrated in Table 5.

\section{Discussion}

This study was undertaken to assess the prevalence of ASD among children referred for the assessment of ID and also to assess the various behavioral and medical problems and its correlation in children with ASD and ID.

(Refer Table 1) The prevalence of ASD among those referred for ID was $16.54 \%$ ( $n=22)$. This is in line with existing studies that cite a prevalence of $15-20 \%$ of ASD among children with ID. ${ }^{18}$ However, these studies have used Childhood Autism Rating Scale and Aberrant Behavior Checklist for the diagnosis of ASD and behavioral issues in this population. In the present study, we have used ISAA and BPI, which are developed and validated in India. In the present study, children with ASD were of significantly younger, which could be possibly because those with comorbid ASD and ID tend to have more severe problems and come to clinical attention at a younger age than those without ASD.
(Refer Table 2) Children with ASD had a higher prevalence of GI symptoms, such as constipation, bloating, and abdominal pain. This is in line with the available literature that describes a prevalence of $9-54 \%$ of Gl symptoms in children with ASD among which constipation, abdominal distension, and diarrhea are common symptoms. Common pathologies as described in previous studies include reflex gastritis, chronic gastritis, duodenitis, and cryptitis, which cause lower digestive enzyme activity leading to the development of the above symptoms. ${ }^{20,22,23}$

Comorbid seizure disorder was seen in $30 \%$ of our study sample. All study subjects with seizure history were with moderate autism. This is in concordance with existing literature that reports an estimated prevalence of epilepsy in children with autism ranging from $4-38 \%$. It is also reported that comorbid epilepsy was associated with higher age, female gender, ID, speech and language delays, and lower socioeconomic status. ${ }^{21}$

There is preliminary evidence to suggest that some common genetic variants link GI abnormalities with ASD. GI abnormalities in turn may be associated with immune dysfunction that may trigger autonomic symptoms and seizures in these individuals. ${ }^{24}$ It is important to recognize this association and assess the presence of these medical symptoms in these children.

(Refer Table 3) In the present study, children with ASD had lower IQ scores and higher behavioral problems, which was reflected in higher scores on total behavioral problems, stereotyped behavior, aggression, and self-injurious behavior domains of BPI. This is in concordance with the literature that states that children with ASD with ID tend to have higher behavioral problems, such as

Table 3: Comparison of IQ, ISAA, and BPI scores among those with and without ASD

\begin{tabular}{lccc}
\hline & $\begin{array}{c}\text { Children with ASD (22) } \\
\text { Mean (SD) }\end{array}$ & $\begin{array}{c}\text { Children without ASD } \\
(n=111) \text { Mean }(S D)\end{array}$ & $\begin{array}{c}\text { t test } \\
(p \text { value })\end{array}$ \\
\hline IQ scores & $47.04(8.72)$ & $56.92(4.52)$ & $7.60\left(0.0001^{\mathrm{a}}\right)$ \\
ISAA scores & $112.83(8.33)$ & $65.85(8.92)$ & $21.94\left(0.0001^{\mathrm{a}}\right)$ \\
BPI-Total severity & $87.75(11.13)$ & $72.13(9.18)$ & $15.42\left(0.001^{\mathrm{a}}\right)$ \\
Self-injurious behavior & $29.9(4.45)$ & $22.34(6.78)$ & $5.42\left(0.001^{\mathrm{a}}\right)$ \\
Stereotyped behavior & $33.24(3.67)$ & $31.85(2.35)$ & $2.31\left(0.02^{\mathrm{a}}\right)$ \\
Aggressive behavior & $17.62(2.14)$ & $12.27(5.32)$ & $4.42\left(0.001^{\mathrm{a}}\right)$ \\
\hline
\end{tabular}

${ }^{\text {Represents }} p \leq 0.05$ considered as statistically significant

Table 4: Comparison of behavioral problems among those with mild and moderate ASD

\begin{tabular}{lcc}
\hline & ISAA (autism) mild & ISAA (autism) moderate \\
\hline Mean BPI scores & 53.00 & 87.12 \\
Standard deviation & 18.26 & 21.08 \\
$n$ & 7 & 13 \\
$p$ value & $0.0046^{\mathrm{a}}$ & \\
\hline
\end{tabular}

Represents $p \leq 0.05$ considered as significant

Table 5: Comparison of autism scores among mild and moderate ID

\begin{tabular}{lcc}
\hline & Mild ID & Moderate ID \\
\hline Mean autism score (ISAA) & 102.83 & 117 \\
Standard deviation & 15.99 & 26.62 \\
$n$ & 8 & 12 \\
$p$ value & \multicolumn{2}{c}{0.2658} \\
\hline
\end{tabular}


self-injurious behaviors, eating abnormalities, and unusual anxieties that may increase with the degree of cognitive impairment. ${ }^{25}$

(Refer Table 4) Children with moderate autism had higher behavioral issues than those with mild autism. This is again in line with the literature that has indicated that ASD severity is associated with a higher prevalence of behavioral problems. ${ }^{26}$

(Refer Table 5) There was no significant difference in autism scores among children with mild and moderate ID. However, it is important to note that measuring cognitive abilities in children with ASD using instruments, such as BKT, does not accurately measure intellectual abilities as these children tend to have impairments in language and communication, which may lead to variability in performance. In addition, measuring intelligence is not reflective of day-to-day functioning in ASD. However, in the present study, we measured intelligence as these children were referred for IQ assessment for disability certification.

This was a cross-sectional study design with purposive sampling. So, the generalization of these findings becomes difficult. Performance-based IQ tests like Raven's progressive matrices that better measure IQ in ASD were not used. Despite these limitations, this study indicated a significant prevalence of ASD among children with ID. These children also had a higher prevalence of medical issues like Gl disturbances and seizures and behavioral problems that increased with severity of autism.

\section{IMPLICATIONS}

There is preliminary evidence for the association between ID and ASD with medical comorbidities and behavioral problems. Knowing more about this association has significant implications on the overall management of these children. There is a need for methodologically robust studies that may have implications for the early detection of these comorbidities and management of these children with ASD.

\section{OrCID}

Shankar Kumar (1) https://orcid.org/0000-0002-8002-4576

Sneha Venkatakrishna (1) https://orcid.org/0000-0002-4575-9446

Sushmitha Kota @ https://orcid.org/0000-0003-0668-4944

\section{References}

1. American Psychiatric Association. Diagnostic and statistical manual of mental disorders. 5th ed. Arlington, VA: American Psychiatric Publishing; 2013.

2. Vivanti G, Barabaro J, Dissanayakke C, et al. Intellectual development in autism spectrum disorders: new insights from longitudinal studies. Front Hum Neurosci 2013;7:354. DOI: 10.3389/fnhum.2013.00354.

3. Chakrabarti S, Fombonne E. Pervasive developmental disorders in preschool children. J Am Med Assoc 2001;285(24):3093-3099. DOI: 10.1001/jama.285.24.3093.

4. Sappok T, Bergmann T, Kaiser $\mathrm{H}$, et al. Autism in adults with mental retardation. Der Nervenarzt 2010;81(11):1333-1345. DOI: 10.1007/ s00115-010-3098-1.

5. Autism Developmental Disabilities Monitoring Network (ADDM). Prevalence of autism spectrum disorders: autism and developmental disabilities monitoring network, 14 sites, United States, 2002. MMWR Surveill Summ 2007;56(SS-1):12-28.

6. Baird G, Charman T, Baron-Cohen S, et al. A screening instrument for autism at 18 months of age: a 6-year follow-up study. J Am Acad
Child Adolesc Psychiatry 2000;39(6):694-702. DOI: 10.1097/00004583200006000-00007.

7. Bertrand J, Mars A, Boyle C, et al. Prevalence of autism in a United States population: the brick township, New Jersey, investigation. Pediatrics 2001;108(5):1155-1161. DOI: 10.1542/peds.108.5.1155.

8. Chakrabarti S, Fombonne E. Pervasive developmental disorders in preschool children. J Am Med Assoc 2001;285(24):3093-3099. DOI: 10.1001/jama.285.24.3093.

9. Chakrabarti S, Fombonne E. Pervasive developmental disorders in preschool children: confirmation of high prevalence. Am J Psychiatry 2005;162(6):1133-1141. DOI: 10.1176/appi.ajp.162.6.1133.

10. Charman T, Pickles A, Simonoff E, et al. IQ in children with autism spectrum disorders: data from the Special Needs and Autism Project (SNAP). Psychol Med 2011;41(3):619-627. DOI: 10.1017/ S0033291710000991.

11. Fombonne E. Epidemiological investigations for autism and pervasive developmental disorders. In: Lord C, editor. Educating children with autism. Washington, DC: National Academy of Sciences Press; 2001.

12. Fombonne E. Epidemiological surveys of autism and other pervasive developmental disorders: an update. J Autism Dev Disord 2003;33(4):365-382. DOI: 10.1023/A:1025054610557.

13. Goin-Kochel RP, Peters SU, Treadwell-Deering D. Parental reports on the prevalence of co-occurring intellectual disability among children with autism spectrum disorders. Res Autism Spectr Disord 2008;2(3):546-556. DOI: 10.1016/j.rasd.2007.11.002.

14. Yeargin-Allsopp M, Rice C, Karapurkar T, et al. Prevalence of autism in a US metropolitan area. J Am Med Assoc 2003;289(1):49-55. DOI: 10.1001/jama.289.1.49.

15. Action for Autism India, 2012. Available from: www.autism-india.org/

16. Centre for Disease Control and Prevention. Available from: http:// www.cdc.gov/mentalhealth/

17. Dawson M, Soulières I, Gernsbacher MA, et al. The level and nature of autistic intelligence. Assoc Psychol Sci 2007;18(8):657-662. DOI: 10.1111/j.1467-9280.2007.01954.x.

18. Nordin V, Gillberg C. ASD in children with physical or mental disability. Dev Med Child Neurol 1996;38(4):297-313. DOI: 10.1111/j.14698749.1996.tb12096.x.

19. Lakhan R. Behavioral management in children with intellectual disabilities in a resource-poor setting in Barwani, India. IJP 2014;56(1):39-45. DOI: 10.4103/0019-5545.124712.

20. Wasilewska J, Jarocka-Cyrta E, Kaczmarski M. Gastrointestinal abnormalities in children with autism. Pol Merkur Lekarski 2009;27(157):40-43.

21. Thomas $S$, Hovinga ME, Rai $D$, et al. Brief report: prevalence of co-occurring epilepsy and autism spectrum disorder: the U.S. National Survey of Children's Health 2011-2012. J Autism Dev Disord 2017;47(1):224-229. DOI: 10.1007/s10803-016-2938-7.

22. Horvath K, Papadimitriou J, Rabsztyn A, et al. Gastrointestinal abnormalities in children with autistic disorder. J Pediatr 1999;135(5):559-563. DOI: 10.1016/s0022-3476(99)70052-1. PMID: 19650428.

23. Horvath K, Perman JA. Autistic disorder and gastrointestinal disease. Curr Opin Pediatr 2002;14(5):583-587. DOI: 10.1097/00008480200210000-00004.

24. Wasilewska J, Klukowski M. Gastrointestinal symptoms and autism spectrum disorder: links and risks - a possible new overlap syndrome. Pediatric Health Med Ther 2015;6:153-166. DOI: 10.2147/PHMT.S85717.

25. Kurzius-Spencer M, Pettygrove S, Christensen D, et al. Behavioral problems in children with autism spectrum disorder with and without co-occurring intellectual disability. Res Autism Spectr Disord 2018;12(56):61-71. DOI: 10.1016/j.rasd.2018.09.002.

26. Lindor E, Sivaratnam C, May T, et al. Problem behavior in autism spectrum disorder: considering core symptom severity and accompanying sleep disturbance. Front Psychiatr 2019;10:487. DOI: 10.3389/fpsyt.2019.00487. 